\title{
Mechanosensory Lateral Line Nerve Projections to Auditory Neurons in the Dorsal Descending Octaval Nucleus in the Goldfish, Carassius auratus
}

\author{
Catherine A. McCormick Shannon Gallagher Evan Cantu-Hertzler \\ Scarlet Woodrick \\ Departments of Biology and Neuroscience, Oberlin College, Oberlin, Ohio, USA
}

\author{
Key Words \\ Nucleus medialis · Mechanosensory lateral line . \\ Descending octaval nucleus
}

\begin{abstract}
The nucleus medialis is the main first-order target of the mechanosensory lateral line (LL) system. This report definitively demonstrates that mechanosensory LL inputs also terminate in the ipsilateral dorsal portion of the descending octaval nucleus (dDO) in the goldfish. The dDO, which is the main first-order auditory nucleus in bony fishes, includes neurons that receive direct input from the otolithic end organs of the inner ear and project to the auditory midbrain. There are two groups of such auditory projection neurons: medial and lateral. The medial and the lateral groups in turn contain several neuronal populations, each of which includes one or more morphological cell types. In goldfish, the exclusively mechanosensory anterior and posterior LL nerves terminate only on specific cell types of auditory projection neurons in the lateral dDO group. Single neurons in the lateral dDO group may receive input from both anterior and posterior LL nerves. It is possible that some of the lateral $\mathrm{dDO}$ neurons that receive $\mathrm{LL}$ input also receive input from one or more of the otolithic end organs. These results are consistent with functional studies demonstrating low fre-
\end{abstract}

quency acoustic sensitivity of the mechanosensory LL in teleosts, and they reveal that the anatomical substrate for sensory integration of otolithic and LL inputs is present at the origin of the central ascending auditory pathway in an otophysine fish.

(c) 2016 S. Karger AG, Basel

\section{Introduction}

All jawed fishes possess mechanosensory lateral line (LL) organs and inner ear auditory and vestibular organs that utilize sensory hair cell receptors. Based on nonexperimental neuroanatomical studies conducted in the early twentieth century, it was concluded that the cranial nerves innervating the mechanosensory LL and auditory organs converge in a common area of the medulla [reviewed in Larsell, 1967]. It was also proposed that the mechanosensory LL system functions as either a 'primitive ear' or an 'accessory auditory organ' [Mayser, 1882; Beard, 1884; Ayers, 1892; Harris and van Bergeijk, 1962; van Bergeijk, 1967]. These assertions contributed to the

S. Gallagher, E. Cantu-Hertzler, and S. Woodrick are undergraduate research contributors to this study.

\section{KARGER}

(c) 2016 S. Karger AG, Basel

E-Mail karger@karger.com

www.karger.com/bbe
Catherine A. McCormick

Departments of Biology and Neuroscience, Oberlin College

Oberlin, Ohio 44074 (USA)

E-Mail Catherine.McCormick@oberlin.edu 


\section{Abbreviations used in this paper}

ALLn anterior lateral line nerve

$\mathrm{AO}$ anterior octaval nucleus

APts auditory projection neurons in the descending octaval nucleus that supply nucleus centralis of the torus semicircularis

C nucleus caudalis

$\mathrm{dDO}$ dorsal portion of the descending octaval nucleus

DO descending octaval nucleus

Ld laterodorsal population of the dorsal portion of the descending octaval nucleus

Ld-f fusiform cell type in the laterodorsal population of the descending octaval nucleus

Ld-pg polygonal cell type in the laterodorsal population of the descending octaval nucleus

Ld-Pk Purkinje-like cell type in the laterodorsal population of the descending octaval nucleus

Ld-rf fusiform cell type in the rostral laterodorsal population of the dorsal portion of the descending octaval nucleus

Ld-s spherical cell type in the laterodorsal population of the descending octaval nucleus

Lhz horizontal cell type in the laterodorsal population of the descending octaval nucleus

LL lateral line

$\mathrm{Lv}$ lateroventral population of the dorsal portion of the descending octaval nucleus

Lv-f vertical fusiform cell type in the lateroventral population of the descending octaval nucleus

Lv-ov spherical/ovoid cell type in the lateroventral population of the descending octaval nucleus

Lv-pg polygonal cell type in the lateroventral population of the of the descending octaval nucleus

M nucleus medialis

Md mediodorsal population of the dorsal portion of the descending octaval nucleus

$\mathrm{Mg}$ magnocellular nucleus

Mvo medioventral ovoid population of the dorsal portion of the descending octaval nucleus

Mvtf medial vertical fusiform population of the dorsal portion of the descending octaval nucleus

PLLn posterior lateral line nerve

PO posterior octaval nucleus

$\mathrm{T}$ tangential octaval nucleus

TS torus semicircularis

VIIIn octaval (eighth) nerve

concept of the 'acousticolateralis system', in which both sensory systems were allied by function and by central anatomy. On the basis of behavioral studies and theoretical considerations, however, Dijkgraaf [1963] and others [reviewed in Sand, 1981] argued that the function of the mechanosensory LL (touch at a distance) was quite separate from the presumed hearing function of the otic auditory system.

Mechanosensory LL Inputs to the dDO
Since then, our understanding of the structure and function of these sensory systems has been clarified and extended by experimental tract-tracing, physiological, and behavioral studies, as well as informed by a more refined understanding of the nature of underwater sound [reviewed in Braun and Sand, 2014]. One point relevant to the current study is that convergence of the inputs from the LL and inner ear auditory organs is minor compared to their distinct termination areas in the medulla in all jawed fishes examined thus far [reviewed in McCormick, 1999; Fay and Edds-Walton, 2008]. Thus, the LL nerves mainly terminate in two first-order mechanosensory LL nuclei, i.e. the nucleus medialis (M) and the nucleus caudalis (C). In contrast, the octaval or eighth nerve (VIIIn) carries sensory fibers from the inner ear to four first-order octaval nuclei - anterior (AO), descending (DO), magnocellular (Mg), and posterior $(\mathrm{PO})$ - and in teleosts to an additional fifth nucleus - tangential (T). Ascending projections to the midbrain from mechanosensory LL and inner ear first-order nuclei are likewise segregated. That is, the ascending output of the M courses to the nucleus ventrolateralis in the midbrain torus semicircularis (TS) [reviewed in Wulliman and Grothe, 2014], whereas that of the dorsal/dorsomedial portion of the $\mathrm{DO}(\mathrm{dDO})$ and the dorsal portion of the AO terminate in the nucleus centralis, the auditory region of the TS. Other portions of the DO and the AO, as well as the $\mathrm{Mg}$ and the $\mathrm{T}$, give rise to projections like those of the vestibular nuclei of other vertebrates [reviewed in Straka and Baker, 2013]. Projections of the remaining first-order nuclei - PO and C - are unknown. Thus, the mechanosensory LL and the otic auditory system utilize largely separate, parallel pathways from their peripheral receptors to the midbrain.

Although the LL and auditory circuits are largely separate, the fact remains that some convergence both in the medulla and in the midbrain TS is known or is likely. LL fibers ramify in the auditory portion of the first-order DO - the dDO - in the goldfish [Puzdrowski, 1989] and in some other species [Bass et al., 2000, and reviews in McCormick, 1999, and Fay and Edds-Walton, 2008]. In two species a small contingent of VIIIn fibers appears to extend into one of the first-order LL nuclei - the M [McCormick and Braford, 1993, 1994]. Convergence of the two sensory systems in the auditory and LL nuclei of the TS has likewise been demonstrated anatomically and/ or electrophysiologically in several species [Schellart and Kroese, 1989; Weeg and Bass, 2000; Fay and Edds-Walton, 2001; Edds-Walton and Fay, 2005]. Furthermore, Higgs and Radford [2013] demonstrated that in the gold- 
fish Carassius auratus the brainstem auditory evoked potentials at 100 and $200 \mathrm{~Hz}$ are a combination of the activity of both the LL canal neuromasts and the inner ear, but they arise only from inner ear activity at higher frequencies. The significance of this observation is that it may reflect the fact that underwater particle motion caused by sound or nonsonic sources that are close to a fish (within 1-2 body lengths) and below $200 \mathrm{~Hz}$ can stimulate both sensory systems [reviewed in Coombs and Montgomery, 1999; Braun and Sand, 2014]. Within the overlapping sensitivity range, processing in the medulla could potentially occur in parallel by LL and auditory nuclei and/or could converge onto common neurons in one or both of these nuclei.

A detailed understanding of the sites of central convergence of the LL and otic auditory systems is relevant to solving the puzzle of the behavioral relevance of their overlapping sensitivity and central integration [e.g. Braun et al., 2000; Braun and Coombs, 2010; Braun and Sand, 2014]. The current study focuses on one area of potential convergence: the auditory region within the $\mathrm{dDO}$ of the goldfish [McCormick and Wallace, 2012]. As noted above, a small number of LL axons extend into this nucleus in the goldfish [Puzdrowski, 1989] and other species. However, axons that extend into the borders of a functional area do not necessarily terminate on its neurons but may instead contact long-reaching processes of cell bodies in other areas.

The auditory region of the goldfish $\mathrm{dDO}$ has been defined as the area that includes neurons that project to the nucleus centralis of the TS. Such neurons were called auditory projection neurons and abbreviated as APts neurons by McCormick and Wallace [2012]. McCormick and Wallace [2012] provisionally subdivided the dDO auditory region into seven populations based on location and cell morphology (fig. 1a). Each population contains one or more cell types, some or all of which receive first-order input from one or more of the inner ear otolithic organs. The most dorsally located APts neurons are proximate to the M. APts neurons located more ventrally are proximate to a cell-sparse zone in the descending nucleus that includes the dendrites of some of the APts neurons [McCormick and Wallace, 2012], as well as neurons with connectional characteristics of vestibular cells (personal observations). Thus, the goals of the current study were (1) to determine whether LL fibers terminate on APts neurons in the $\mathrm{dDO}$ and, if so, (2) to determine which cell types within the seven APts population receive LL input, thereby providing information relevant to auditory processing.

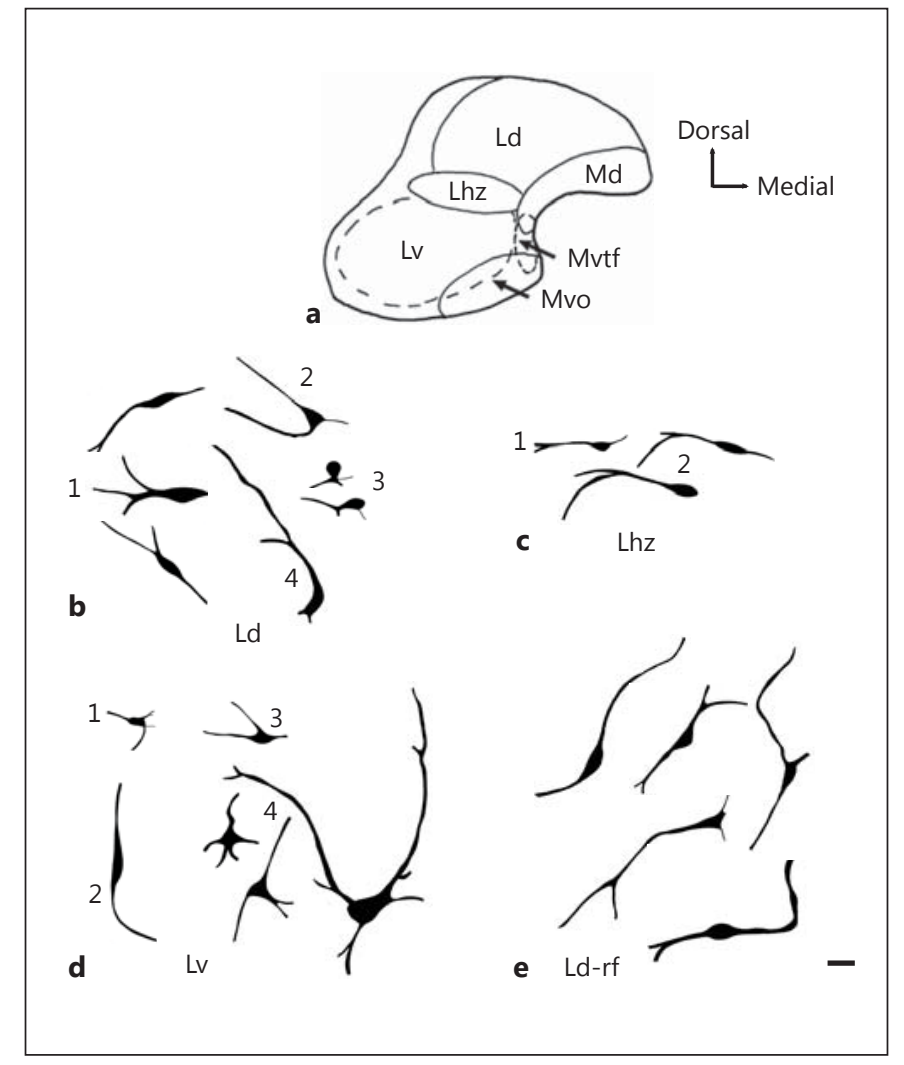

Fig. 1. a Line drawing of a transverse section through the dDO showing the locations of six of the seven populations of APts neurons (neurons that project to the auditory midbrain). Three populations are medial: Md, Mvtf, and Mvo. The three populations at this level that are lateral are: Ld, Lhz, and Lv. A fourth lateral population, i.e. Ld-rf, is present rostral to the level of this figure [after McCormick and Wallace, 2012]. b-e APts cell types in the four lateral populations. The orientation in a applies to each cell type. However, the grouping of cell types does not reflect their location in a given population. $\mathbf{b}$ APts cell types in the Ld: Ld-f (1), Ld-pg (2), Ld-s (3), Ld-Pk (4). c APts cell types in the Lhz: cell type with a smaller soma and a distinct U-shaped dendritic ending (1), and cell type with a larger soma and a branched dendrite (2). d APts cell types in the Lv: Lv-s (1), Lv-f (2), Lv-pg triangular (3), and Lv-pg multipolar (4). e APts cell types in the Ld-rf. Scale bar for b-e $=20 \mu \mathrm{m}$.

\section{Materials and Methods}

Eleven goldfish ranging in standard length from 4 to $8 \mathrm{~cm}$, obtained from local dealers, were used in this study. The methods followed those described in the study of McCormick and Wallace [2012]. Fish were deeply anesthetized with buffered MS-222 (Sigma), perfused transcardially with cold $\left(4^{\circ} \mathrm{C}\right)$ oxygenated artificial cerebrospinal fluid at $\mathrm{pH}$ 7.2-7.4 [Zupanc, 1998], and placed on a cold block during exposure of the dorsal surface of the TS and exposure of the LL nerves. To maximize retrograde labeling in 
the $\mathrm{dDO}$, in each fish, Neurobiotin (Vector Labs) adhered to the tips of minuten pins was introduced 4-6 times along the rostrocaudal length of the TS on each side. A given LL nerve was exposed close to its entry into the medulla and severed. Pins coated with fluorescent dextran were placed against the cut surface proximal to the brain. In 6 brains, one LL nerve on each side of the brain was implanted with Alexa Fluor dextran 488 (Invitrogen). In 5 brains, two LL nerves were implanted on one side - one with Alexa Fluor dextran 488 and the other with Alexa Fluor dextran 647. In two of the latter brains, a single LL nerve was also labeled with Alexa Fluor dextran 488 on the other side.

After all tracers had been implanted, much of the remainder of the dorsal surface of the skull was removed, the rostral spinal cord was severed, and the head was placed in a beaker containing continuously oxygenated artificial cerebrospinal fluid ( $\mathrm{pH} 7.2-7.4)$ at $4^{\circ} \mathrm{C}$ for $32-48 \mathrm{~h}$. The preparation was then fixed by immersion for $2 \mathrm{~h}$ in a $4^{\circ} \mathrm{C}$ solution of $4 \%$ paraformaldehyde and $2 \%$ glutaraldehyde, after which the brain was removed and placed in fresh cold fixative for $24-30 \mathrm{~h}$ followed by cryoprotection in $30 \%$ sucrose in $0.1 \mathrm{M}$ phosphate buffer ( $\mathrm{pH} 7.4$ ) at $4^{\circ} \mathrm{C}$ for $1-3$ days. The brains were then embedded in a solution of $12.5 \%$ gelatin and $10 \%$ sucrose in a $0.2 \mathrm{M}$ phosphate buffer solution. The gelatin blocks were fixed ( $24 \mathrm{~h}$ ) and cryoprotected (1-3 days) as described above and then sectioned with a freezing microtome on the transverse plane at $60 \mu \mathrm{m}$ into $0.1 \mathrm{M}$ phosphate buffer. Neurobiotin was visualized using streptavidin conjugated to Alexa Fluor 555 or 597 (Invitrogen), after which the sections were mounted on slides and coverslipped with ProLong Gold (Invitrogen) or Vectashield (Vector Labs) in cases where nerves were only labeled with Alexa Fluor dextran 488.

Brain sections were imaged and analyzed using a Zeiss LSM-5 Pascal confocal microscope. Alexa Fluor dextran 488 labeling was false-colored green, Alexa Fluor dextran 647 labeling was false-colored blue, and Alexa Fluor 555/597 labeling was false-colored red. Brain sections were imaged at low power in order to record the locations of terminals visualized at higher powers. Inputs were verified by rotating three-dimensional reconstructions of $\mathrm{Z}$ stacks collected at high power. In addition to the 11 brains analyzed for terminal inputs, two sets of cresyl violet-stained sections prepared for previous studies were used as references for nuclear boundaries.

This study was approved by the Oberlin College Institutional Animal Care and Use Committee.

\section{Results}

Most fibers in the anterior and posterior LL nerves (ALLn and PLLn) aggregate into the ALL and PLL tracts upon entering the medulla. These tracts ascend and descend within the $\mathrm{M}$ in a region referred to as the deep neuropil layer by New et al. [1996]. At each level, some fibers within these tracts ramify within the $M$, supplying at least the ventral dendrites of its crest cell layer. The ascending LL tracts eventually terminate in the eminentia granularis of the cerebellum, and the descending tracts continue to the small $\mathrm{C}$, caudal to the $\mathrm{M}$. At levels where the anterior ramus of the VIIIn enters the medulla, a small subset of LL nerve fibers extends medially beyond the boundary of the $\mathrm{M}$ and supplies the $\mathrm{Mg}$. In the current paper, we provide direct evidence that other LL fibers supply the $\mathrm{dDO}$ at all but its most caudal levels. The contacts that these latter fibers make with specific cell types in the $\mathrm{dDO}$ are described below. Except as noted in table 1, LL input to each cell type was observed in 2 or more brains. It was usual to see LL input to a specific cell type in a given brain more than once.

\section{LL Inputs to the $d D O$}

We observed no qualitative difference between the inputs of the ALLn and the PLLn to the dDO. These inputs were restricted to certain cell types within the lateral portion of the $\mathrm{dDO}$. The lateral portion of the $\mathrm{dDO}$ contains, at most levels, 3 populations of neurons: laterodorsal (Ld), laterohorizontal (Lhz), and lateroventral (Lv). At rostral levels of the $\mathrm{dDO}$, an additional rostral laterodorsal fusiform (Ld-rf) population replaces the Ld [fig. 1a; McCormick and Wallace, 2012]. Each population contains several cell types (fig. 1b-e). The data discussed below are summarized in table 1 , which also lists inputs from the inner ear otolithic end organs [McCormick and Wallace, 2012] to these cell types.

\section{LL Inputs to the Ld and the Ld-rf}

The majority of neurons in the Ld are morphologically fusiform (Ld-f; 1 in fig. 1b) or polygonal (Ld-pg; 2 in fig. $1 b)$. The Ld-f and the Ld-pg receive somatic and dendritic inputs from the ALLn and the PLLn (fig. 2a, b). The inputs on the ventral and/or lateral dendrites of these neurons are far more numerous compared to inputs in other regions of the cell (fig. 2a, b). Somata and the ventral/lateral dendrites of the Ld-f receive input from both LL nerves. We observed colabeling by both ALLn and PLLn on Ld-pg somata. However, we observed many ventral dendrites that very likely belong to either the Ld-f or the Ld-pg but were not connected to a soma, and these, too, received numerous LL inputs, including input from both LL nerves. Thus, it is possible that Ld-pg ventral and lateral dendrites are also supplied by both LL nerves.

Similarly to the Ld-f and the Ld-pg, the ventral/ventrolateral and dorsolateral dendrites of Ld-rf cells (fig. 1e) receive many LL contacts, while somata are less well supplied (fig. 2c, d). Some somata are colabeled. We saw only one case of input to a dorsomedial dendrite. This neuron has a PLL contact on a dorsomedial dendrite and an ALL contact on a ventral dendrite.

We observed no LL input to the two other cell types in the Ld, i.e. Ld-s (3 in fig. 1b) and Ld-Pk (4 in fig. 1b). 
Table 1. APts cell types in the Ld, Ld-rf, Lhz, and Lv populations and their inputs from the mechanosensory LL nerves and from the otolithic end organs of the inner ear

\begin{tabular}{|c|c|c|c|c|c|c|c|c|}
\hline $\begin{array}{l}\text { Cell } \\
\text { type }\end{array}$ & Region of the neuron & ALLn & PLLn & \multicolumn{5}{|c|}{ Input to cell type } \\
\hline \multirow[t]{3}{*}{ Ld-f } & \multirow{3}{*}{$\begin{array}{l}\text { soma } \\
\text { dorsal dendrite } \\
\text { ventral/lateral dendrite }\end{array}$} & + & + & + & + & - & - & \multirow{3}{*}{$* 1$} \\
\hline & & + & + & - & - & - & - & \\
\hline & & ++ & ++ & + & + & + & ++ & \\
\hline \multirow{2}{*}{ Ld-pg } & \multirow{2}{*}{$\begin{array}{l}\text { soma } \\
\text { dorsal dendrite } \\
\text { ventral/lateral dendrite }\end{array}$} & + & + & - & - & - & - & \\
\hline & & ++ & ++ & - & + & + & ++ & \\
\hline \multirow{3}{*}{$\begin{array}{l}\text { Ld-Pk; } \\
\text { Ld-s }\end{array}$} & \multirow{3}{*}{$\begin{array}{l}\text { soma } \\
\text { dorsal dendrite } \\
\text { ventral dendrite }\end{array}$} & - & - & - & $-^{*}$ & $++^{b, c}$ & \multicolumn{2}{|l|}{-} \\
\hline & & - & - & - & -* & $++^{b, c}$ & - & \\
\hline & & - & - & - & -* & $+^{b, c}$ & - & \\
\hline Lhz & soma & ++ & ++ & + & + & ++ & - & $* 3$ \\
\hline & dendrites & ++ & ++ & + & + & ++ & ++ & 3 \\
\hline Lv-ov & soma & ++ & ++ & + & + & + & + & $*_{4}$ \\
\hline & dendrites & + & + & + & - & - & - & 4 \\
\hline$L v-f$ & soma & ++ & ++ & + & + & + & - & \\
\hline & dorsal dendrite & ++ & + & + & - & - & - & $* 5$ \\
\hline & ventral dendrite & ++ & + & + & + & + & + & \\
\hline Lv-pg & soma & ++ & ++ & + & + & + & + & \\
\hline multipolar & dendrites & ++ & ++ & + & + & + & + & 76 \\
\hline Lv-pg & soma & $+*$ & - & - & + & - & - & \\
\hline
\end{tabular}

This study did not directly address whether or not LL and inner ear inputs converge onto common neurons. Inner ear inputs are from McCormick and Wallace [2012]. + and $++=$ Relative amount of observed input; $+^{*}=$ only one observation of input; $-=$ no input observed; $-^{*}=$ no input may be due to the sample size; ${ }^{*} 1=$ convergence of input from utricle and lagena; ${ }^{*} 2=$ convergence of input from utricle and saccule; $* 3=$ convergence of input from utricle and lagena; $* 4=$ convergence of input from saccule and utricle, data not indicated in table 3 of McCormick and Wallace [2012]; ${ }^{*} 5=$ convergence of input from utricle and saccule; $* 6=$ convergence of input from utricle and saccule and from utricle and lagena. ${ }^{a}$ Dendrites of 1 soma. ${ }^{b} \mathrm{Ld}-\mathrm{Pk} .{ }^{\mathrm{c}} \mathrm{Ld}-\mathrm{s}$.

\section{LL Inputs to the Lhz}

Lhz somata and dendrites (fig. 1c) both receive numerous contacts from the LL nerves (fig. $2 \mathrm{~b}, 3 \mathrm{a}$ ). Convergent input, i.e. input from both LL nerves, occurs at both locations. None of the LL inputs were large hook-like contacts that at least some of these neurons receive from the utricular branch of the VIIIn [McCormick and Wallace, 2012].

\section{LL Inputs to the $L v$}

The Lv of the dDO contains ovoid (Lv-ov; 1 in fig. 1d), fusiform (Lv-f; 2 in fig. 1d), and polygonal neurons (Lv-pg; 3 and 4 in fig. 1d). We observed LL input to all Lv cell types.
The somata and dendrites (both dorsal and ventral) of Lv-f neurons are colabeled by both LL nerves (fig. 3b, c). The apparently greater input from the ALLn compared to the PLLn may be a result of the sample size rather than a real difference.

LL inputs to Lv-ov somata were common and usually numerous (fig. 3d). Some somata get input from both the ALLn and the PLLn. We twice observed a small LL input (from both the ALL and the PLL in one case) on a dendrite proximal to the soma.

There are two morphological types of Lv-pg neurons: neurons with a triangular soma with a dendrite emerging 

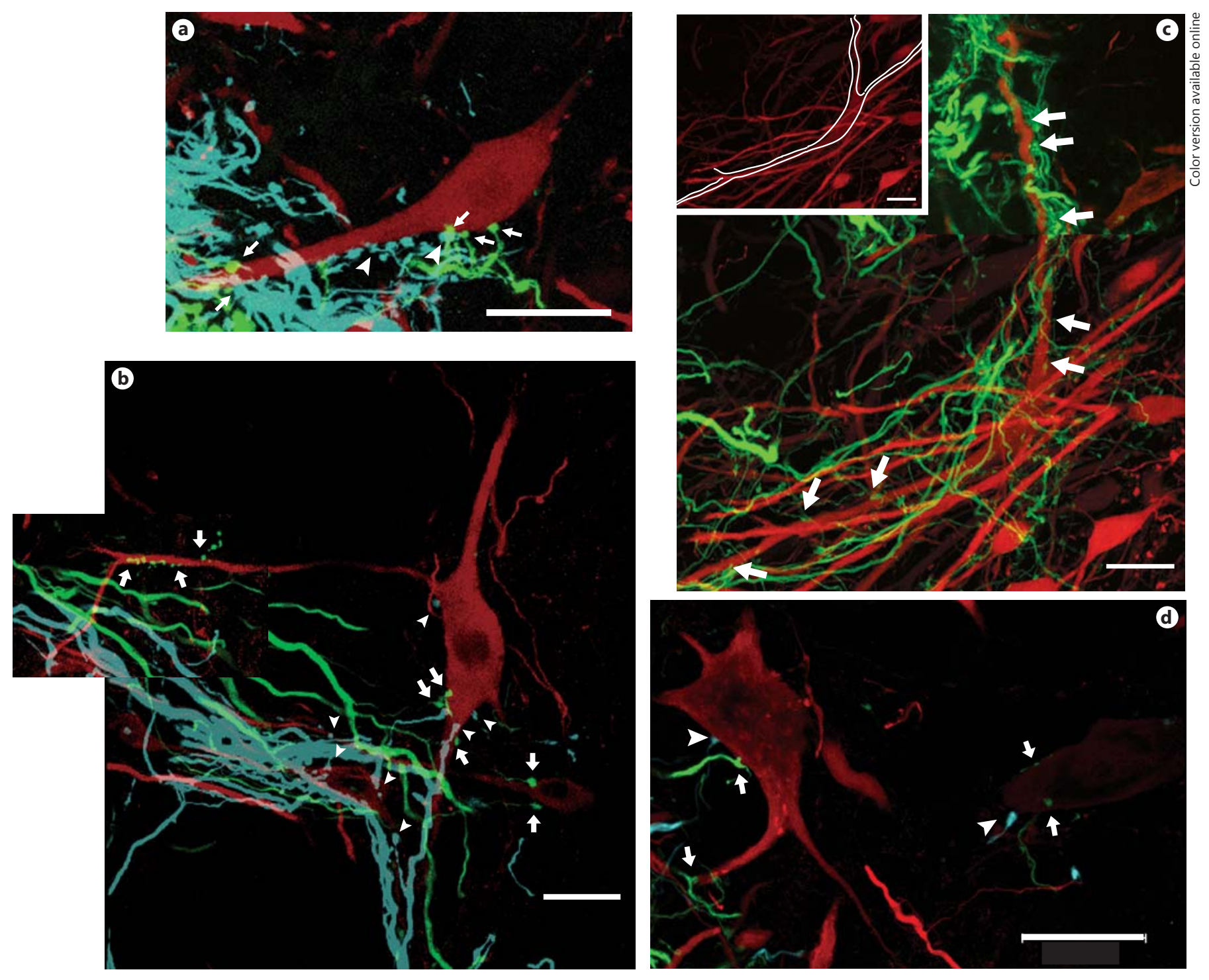

Fig. 2. a An Ld-f neuron with ALLn input (arrowheads, blue false color) on its ventral dendrite and PLLn input (arrows, green false color) on its soma and ventral dendrite. Scale bar $=20 \mu \mathrm{m}$. b An Ld-pg neuron with ALLn input (arrowheads, blue false color) on its soma, lateral dendrites, and a ventral dendrite and PLLn input on its soma and ventral dendrite (arrows, green false color). The lateral extension of this figure is on a different plane of focus in order to see the neuron's lateral dendrite. A portion of another type of Ld-pg neuron, located to the left of the ventral dendrite of the aforementioned Ld-pg neuron, has ALLn input (arrowheads, blue false color) on its soma and ventral dendrite. One of the more dorsally located Lhz neurons, seen to the right of the Ld-pg ventral dendrite, has ALLn input (arrowhead, blue false color) on its lateral dendrite and PLLn input (arrows, green false color) near its soma. Scale bar $=20 \mu \mathrm{m}$. c Ld-rf neuron with many PLLn (arrows, green false color) contacts on its dorsolateral and ventral dendrites. The inset shows the outline of the neuron. Neither the dorsolateral nor the dorsomedial dendrites of this neuron could be completely followed. However, the dorsolateral dendrite curves laterally towards the $\mathrm{M}$, while the dorsomedial dendrite extends towards the cerebellar crest. Scale bars $=20 \mu \mathrm{m}$. d Two Ld-rf neurons. The neuron on the left has somatic input from the ALLn (arrowhead, blue false color) and PLLn (arrow, green false color) and PLLn input to a ventral dendrite (arrow, green false color). The neuron on the right has somatic input from the ALLn (arrowhead, blue false color) and PLLn (arrows, green false color). Scale bar = $20 \mu \mathrm{m}$. Colors refer to the online version only. 

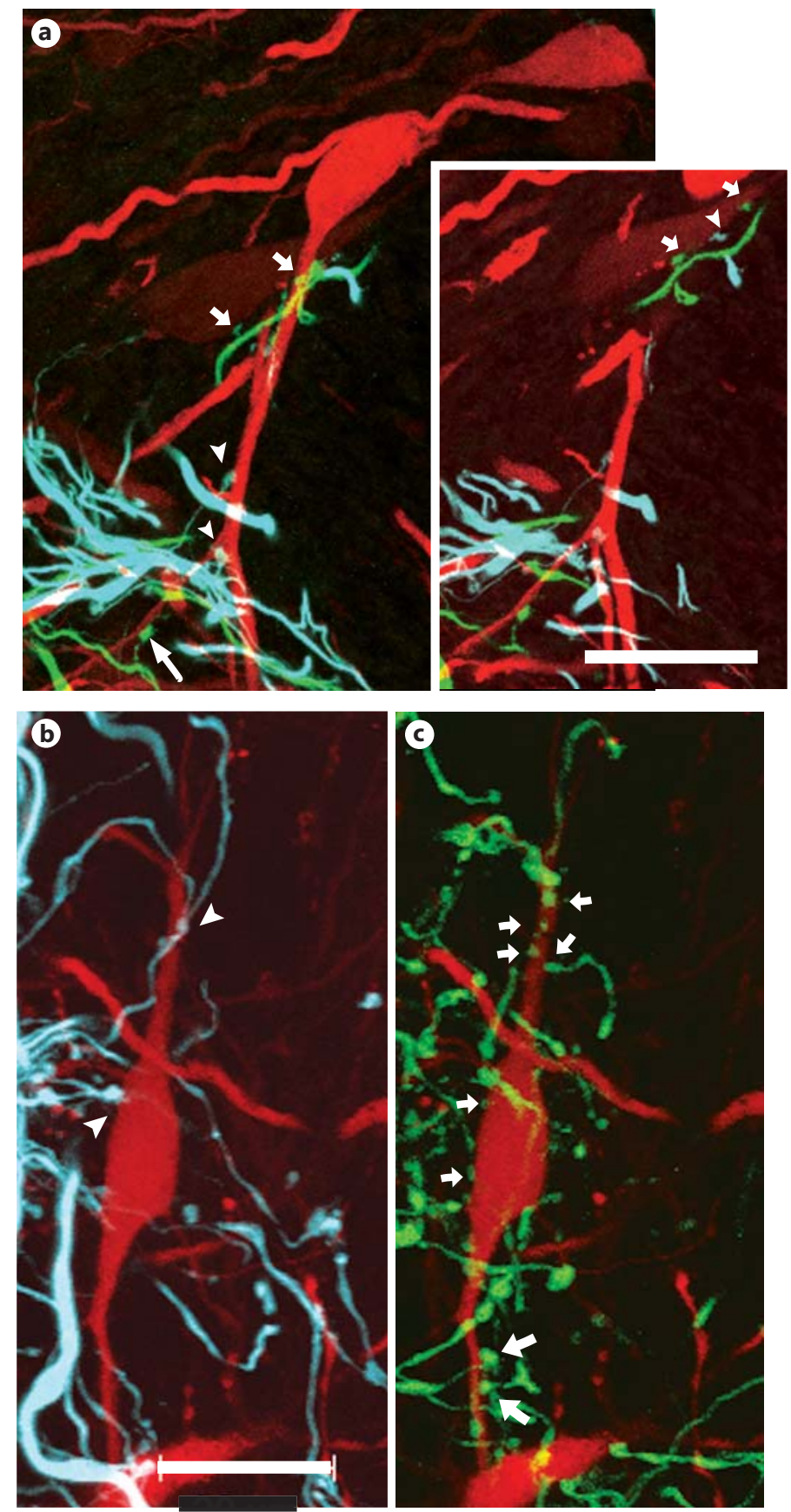

Fig. 3. a Two Lhz neurons. The darker neuron on the right has ALLn input (arrowheads, blue false color) on the shaft and the branch point of its ventrolateral dendrite and PLLn input (arrows, green false color) on its ventrolateral dendrite near the soma and distal to the branch point. The lighter neuron on the left is shown more clearly in the inset, which is on a different plane of focus. The latter neuron has somatic input from the ALLn (arrowhead, blue false color) and PLLn (arrows, green false color). Scale bar $=20 \mu \mathrm{m}$. b Lv-f neuron with ALLn input (arrowheads, blue false color) on its soma and dorsal dendrite. Scale bar $=20 \mu \mathrm{m}$. c Lv-f neuron in b with PLLn input (arrows, green false color) on its soma and its
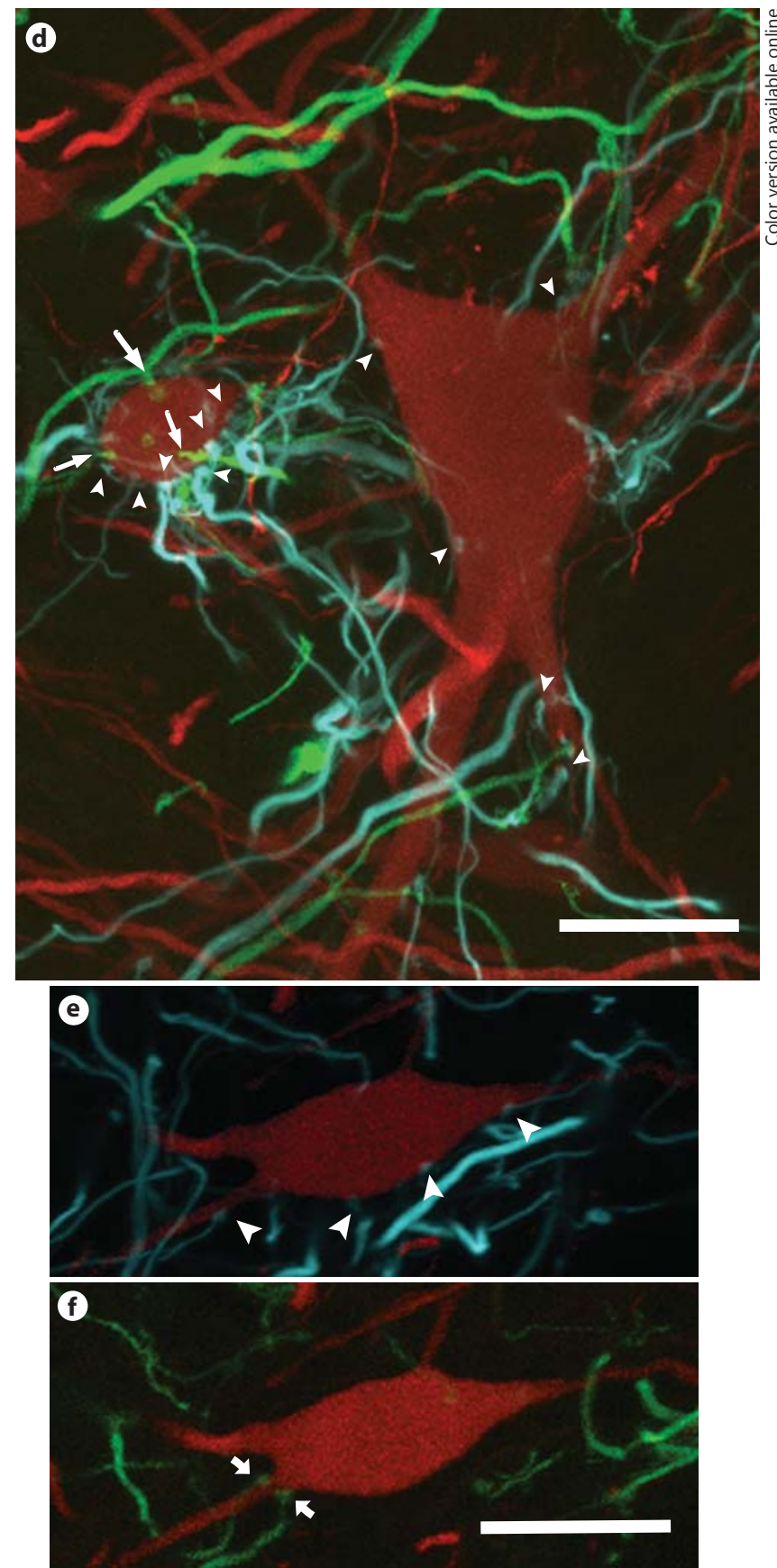

dorsal and ventral dendrites. $\mathbf{d}$ Lv-ov neuron on the left with numerous somatic contacts from the ALLn (arrowheads, blue false color) and PLLn (arrows, green false color). Lv-pg multipolar neuron on the right with ALLn input (arrowheads, blue false color) on its mediodorsal and medioventral dendrites and soma. Scale bar $=$ $20 \mu \mathrm{m}$. e Lv-pg multipolar neuron with ALLn contacts (arrowheads, blue false color) on its soma and ventrolateral dendrite. f Lv-pg multipolar neuron in e with PLLn contacts (arrows, green false color) on its ventrolateral dendrite. Scale bar $=20 \mu \mathrm{m}$. Colors refer to the online version only. 
from each edge, and multipolar neurons with four or more primary dendrites. Multipolar Lv-pg neurons can receive many LL inputs on the soma and various dendrites; we also observed convergent input (i.e. input from both LL nerves) at both locations (fig. 3d-f). However, we saw LL input to only a single Lv-pg triangular neuron; this input was from the ALLn on the soma and dendrites.

\section{Other Observations}

We traced no LL inputs to the three populations in the medial dDO: Md, Mvtf, and Mvo. We also saw no LL inputs to the $\mathrm{AO}$, the $\mathrm{PO}$, or the secondary octaval population.

\section{Discussion}

Our goal was to determine which APts neurons in the $\mathrm{dDO}$, if any, receive input from the LL nerves. We observed no LL input to the 3 medial APts populations in the dDO, but we found that all 3 of the lateral APts populations in the main part of the $\mathrm{dDO}-\mathrm{Ld}, \mathrm{Lhz}$, and $\mathrm{Lv}-$ plus a rostral dDO population - Ld-rf - include at least some cell types that receive LL input (table 1). APts neurons receive primary input from the otolithic end organs (table 1) and project to the auditory midbrain - the nucleus centralis of the TS [McCormick and Wallace, 2012]. Presumably, other auditory $\mathrm{dDO}$ neurons are present but output to structures other than the auditory midbrain; the morphology of such neurons, including the specific source(s) of their input from peripheral or central structures, is unknown.

We did not determine whether a given APts neuron receives both LL and otolithic end organ input. It is possible that the lateral $\mathrm{dDO}$ has segregated zones for LL and auditory processing, but, as discussed below, this seems unlikely for at least some cell types. The lack of functional information hinders speculations about the types of processing carried out by different morphological types. Nevertheless, some working hypotheses are presented below.

\section{Characteristics of the Ld and the Ld-rf}

The following APts cell types in the Ld population Ld-f, Ld-pg, and Ld-rf - are likely significant first-order integration points for the LL and auditory systems. We have not quantified the number of these neurons in the $\mathrm{dDO}$, but, based on retrograde labeling from the nucleus centralis of the TS and an analysis of cresyl violet-stained sections, these Ld cell types appear to be much more numerous than any of the other cell types in the lateral dDO.
The ventral dendrites of Ld-f, Ld-pg, and Ld-rf neurons receive many contacts from the ALLn and the PLLn. As noted in a previous study, the ventral dendrites of these neurons receive many contacts from VIIIn branches from the otolithic end organs, most notably the utricle (table 1). Ld-f and Ld-rf ventral dendrites are coinnervated by the ALLn and the PLLn (present study) and by the utricle and lagena [McCormick and Wallace, 2012]. These cell types also receive various, lighter inputs from the LL and the inner ear on other parts of the cell (table 1). On the one hand, because there are so many Ld/Ld-rf neurons, it is possible that some neurons process only otic information and others only LL input. If this were the case, however, LL-innervated Ld/Ld-rf ventral dendrites might be expected to be confined to certain areas and those with otolithic branch input confined to other regions. This type of segregated input pattern was discerned neither in the current study nor in that of McCormick and Wallace [2012]. Given the current information, therefore, it is reasonable to suggest that Ld/Ld-rf cell types, comprising a significant portion of the $\mathrm{dDO}$ and in receipt of numerous inputs from ALLn, PLLn, and otolithic end organs, are likely candidates for sites of sensory integration.

The Ld-f, the Ld-pg, and the Ld-rf share common morphological features. Their ventral dendrites receive first-order sensory input (from the otolithic end organs, from the LL, or potentially from both). In contrast, their dorsal/apical dendrites extend into an overlying molecular layer, i.e. the cerebellar crest, where they receive descending input from axons from the eminentia granularis of the cerebellum and the nucleus praeeminentialis [reviewed in Finger, 1986; Yamamoto et al., 2010]. This anatomical arrangement is similar to the 'cerebellum-like' circuitry of comparable neurons in the first-order LL electrosensory and mechanosensory nuclei of gnathostome fishes [reviewed in Bell, 2002, and in Bell et al., 2008]. Physiological studies of the two LL modalities indicate that this circuitry forms an adaptive filter capable of improving signal-to-noise ratios [Montgomery and Bodznick, 1993, 1994, 1999; Bell et al., 1997; Bodznick et al., 1999; reviewed in Bell, 2002, and Bell et al., 2008]. It is not unreasonable to hypothesize that this also takes place in the $\mathrm{dDO}$. It is interesting to note that in mammals a similar anatomical arrangement in the dorsal cochlear nucleus may be involved in the processing of spectral cues that contribute to sound localization [Young et al., 1992; Oertel and Young, 2004]. 
Characteristics of Lv-f and Lv-pg Multipolar Neurons

Although Lv-f neurons are not numerous, they are consistently retrogradely labeled from the nucleus centralis of the TS. Each neuron is oriented on either the dorsoventral or the mediolateral plane and appears to be bipolar, although we have not labeled dendrites out to their endings. Both the somata and the dendrites are colabeled by the LL nerves. Otolithic end organ branches also supply and coinnervate these neurons [McCormick and Wallace, 2012]. More LL input to the Lv-f was noted in the current study than was observed from the otolithic end organs by McCormick and Wallace [2012]; whether this difference is real or resulted from a sampling bias is unknown.

Compared to Lv-f neurons, fewer Lv-pg multipolar cell neurons are filled after injection of Neurobiotin into the nucleus centralis. The LL nerves colabel somata and dendrites. Otolithic end organ branches colabel dendrites; the utricle also provides input to somata [McCormick and Wallace, 2012]. In contrast to many observations of LL input to Lv-pg multipolar neurons, we noted LL input to only one Lv-pg triangular cell. In this case, the ALLn terminated on the soma and dendrites. Lv-pg triangular neurons receive dendritic input from all of the otolithic end organs and somatic input from the saccule. It is possible that the single case of LL input to this cell type that we observed resulted from a sampling bias.

Because there is only a small number of Lv-f and Lv-pg neurons, it is unlikely that there are separate populations receiving only LL or only otic input. Moreover, the dendrites of these neurons appear to be long and may well ramify in other parts of the $\mathrm{dDO}$ or in the M. For example, multipolar Lv-pg neurons with very-large-diameter somata, as seen in figure 1d (4), have a long dorsolateral dendrite that potentially extends into regions of the lateral dDO that contain first-order vestibular neurons. Since there is a small number of vestibulospinal neurons lateral to the dDO APts neurons (McCormick, pers. observation), it is possible that large multipolar Lv-pg neurons could receive input on their dorsolateral dendrite from afferents innervating these vestibulospinal neurons or from axon collaterals of vestibulospinal neurons. It is also possible that Lv-pg dorsolateral dendrites might ramify into the deep neuropil layer of the $\mathrm{M}$ and thus receive additional primary LL input or input from neurons in the $\mathrm{M}$.

\section{Characteristics of Lhz Neurons}

The soma and dendritic shaft of Lhz neurons are coinnervated by the ALLn and the PLLn. Some Lhz neurons also receive input from more than one otolithic end organ, with the soma receiving most of its input from the lagena [McCormick and Wallace, 2012]. The Lhz is one of 2 populations in the $\mathrm{dDO}$ that additionally receive large, distinctive contacts from the utricle [McCormick and Wallace, 2012]. In one of the two Lhz cell types, a lobulated ending can be present at the dendritic tip ( 1 in fig. 1c). In the other cell type U-shaped endings are located at the distal end of the primary dendrite between the area from which the two secondary dendrites emerge ( 2 in fig. 1c). The other population - Mvo cells - is also a site of otolithic end organ convergence and it receives its heaviest somatic contacts from the saccule; however, we observed no first-order LL input to Mvo. It is possible that the large utricular contacts modulate Lhz activity in a specific, as yet unknown, way. If LL and otolithic end organ inputs converge on common Lhz cells, such modulation is likely to be quite complex.

\section{Characteristics of Lv-ov Neurons}

Lv-ov somata are small (10-15 to $15-20 \mu \mathrm{m})$ and generally located in the most lateral region of the Lv [fig. $5 \mathrm{~b}$ in McCormick and Wallace, 2012]. Individual Lv-ov somata receive a large number of contacts from the LL nerves and at least some are innervated by both LL nerves. Lv-ov somata may also be innervated by one or more otolithic end organs [McCormick and Wallace, 2012]. The $\mathrm{Lv}-\mathrm{ov}$ has a long rostrocaudal extent within the $\mathrm{dDO}$ of the goldfish. It is the only Lv cell type that extends from more rostral levels of the $\mathrm{dDO}$ (though not from its rostral limit) to the caudal-most dDO level [McCormick and Wallace, 2012].

Despite its long rostrocaudal extent, the Lv-ov occupies a very small area in a given cross-section. This suggests that, if LL and otic inputs do not converge onto single neurons, there may be modality-specific regions organized on the rostrocaudal plane. It seems more likely, however, that the Lv-ov is a site of sensory integration.

\section{Comparison with Other Studies}

The initial part of the central LL circuit and that of the central auditory circuit are mainly separate [reviewed in McCormick, 1999, and Fay and Edds-Walton, 2008], but there are reports that both of these sensory systems send some fibers to common first-order areas. Of particular relevance to the current study are observations of LL nerve fibers within, or terminating in, the lateral $\mathrm{dDO}$ in goldfish as well as in other species of fish [O'Marra and McCormick, 1999; Bass et al., 2000; reviews by McCormick, 1999, and Fay and Edds-Walton, 2008]. Inputs have
76

Brain Behav Evol 2016;88:68-80 DOI: $10.1159 / 000447943$
McCormick/Gallagher/Cantu-Hertzler/ Woodrick 
been assumed though not unequivocally proven. For instance, LL fibers might instead contact the ventral dendrites of medially located nucleus $M$ cells. The current study provides direct evidence that the LL nerves supply certain cell types in the goldfish lateral dDO. It is thus possible that the $\mathrm{dDO}$ receives LL input in other species of bony fish.

There are no systematic studies of $\mathrm{dDO}$ cell types in other species that enable a direct comparison of these cell types with those in the goldfish, although, as discussed below, it is possible that the Ld-f neurons are found in all teleosts. Comparative analyses of the locations and morphology of cell types within the entire $\mathrm{dDO}$ would contribute to an understanding of both its functional regions and its evolution and variations among osteichthyans.

Other areas of the brainstem are thought to receive both LL and VIIIth nerve inputs. A very small number of otolithic end organ fibers ramify in the $\mathrm{M}$ in the catfish [from the saccule and lagena; McCormick and Braford, 1993] and in the goldfish [from the saccule, McCormick and Braford, 1994]. If confirmed, this putative input requires further study. It has been long known that the VIIIth and LL nerves project strongly to the eminentia granularis (actinopterygians) and the lateral granular area (chondrichthyans) of the cerebellum [reviewed in McCormick, 1999, and in Fay and Edds-Walton, 2008]. As noted above, these cerebellar areas contribute to 'cerebellum-like' circuits that modulate the activity of specific types of neurons in the electrosensory first-order nucleus, in the M, and potentially in the $\mathrm{dDO}$. The Mg has also been consistently reported as receiving input from both the inner ear (the specific end organs are incompletely known) and, in most species, the LL [reviewed in McCormick, 1999; Tomchik and Lu, 2005; Maruska and Tricas, 2009]. Because the Mg projects to the spinal cord but not to the midbrain, it is likely a sensorimotor nucleus that integrates LL and otic vestibular and/or auditory inputs [reviews in McCormick, 1999, and in Edds-Walton et al., 2013]. Similarly, the Mauthner neuron is a sensorimotor structure that receives input from the 3 otolithic end organs [Szabo et al., 2007] and from the mechanosensory LL [Mirjany et al., 2011] and outputs to the spinal cord [reviewed in Eaton et al., 2001].

Convergence of the otic and LL sensory systems also occurs at higher levels of the brainstem. In the plainfin midshipman Porichthyes notatus, the M projects to the auditory divisions of the descending nucleus (comparable to the goldfish $\mathrm{dDO}$ ) and to the $\mathrm{Mg}$, and some neurons in the latter project to the M [Weeg and Bass, 2000]. In the midbrain TS, both anatomical and physiological stud- ies in a variety of species have demonstrated some convergence of LL and auditory inputs [Schellart and Kroese, 1989; Weeg and Bass, 2000; Fay and Edds-Walton, 2001; Edds-Walton and Fay, 2005].

\section{Functional Considerations}

Our results, definitively demonstrating that certain cell types in the lateral $\mathrm{dDO}$ receive input from the mechanosensory LL in addition to the otolithic end organs, may reflect the primitive condition for jawed fishes. Sound, as well as nonsonic sources, such as the communication or schooling movements of fish [reviewed in Webb et al., 2008], produces local incompressible flows and far ranging propagated pressure waves. The local incompressible flows are capable of stimulating the mechanosensory LL at low frequencies $(\sim 1-200 \mathrm{~Hz})$ within short distances (within 1-2 body lengths of the fish). Therefore, if a fish is close to the source of sound/water movement with an upper limit of $200 \mathrm{~Hz}$, both the mechanosensory LL and the otolithic end organs may be stimulated [reviewed in Coombs and Montgomery, 1999; Braun and Sand, 2014; Higgs and Radford, 2016].

Using the goldfish, Higgs and Radford [2013] were the first to demonstrate that at 100 and $200 \mathrm{~Hz}$ the auditory evoked potential is a combination of the activity of both the LL canal neuromasts and the otic auditory organs, whereas at higher frequencies it results only from the inner ear. They suggest that published auditory evoked potentials in other species may well reflect the overlapping sensitivities of these two modalities at low frequencies [Higgs and Radford, 2016]. Indeed, responses to the lowfrequency components of species-specific vocalization have been demonstrated for the superficial LL neuromasts in the plainfin midshipman [Weeg and Bass, 2002] and for the ALLn in the related oyster toadfish [Radford and Mensinger, 2014].

A number of hypotheses have been put forth about the behavioral relevance of overlapping sensitivity and central integration of LL and otic acoustic inputs. Interaction between the two modalities may influence close-range mating or aggressive behaviors [Weeg and Bass, 2002; Higgs and Radford, 2016]. Braun and Coombs [2010] provided evidence in the mottled sculpin Cottus bairdi that the LL and auditory systems might be used either in series or in parallel according to specific behavioral contexts. More generally, the LL system might contribute information that enhances the inner ear's role in sound localization [Zeddies et al., 2010; Radford and Mensinger, 2014], for instance via complementation or synergy [Braun et al. 2000; Coffin et al., 2014]. Higgs and Radford 
[2016] pointed out that the focus on the inner ear alone in the study of fish hearing should be expanded to include the contributions of the mechanosensory LL in experiments designed to explore behaviors that may well be dependent on integration of the 2 modalities.

\section{Speculations about the Primitive Auditory Pathways}

This study focused on the goldfish because the auditory system of this species is among the best studied within the vertebrate class Osteichthyes - the bony fishes. However, the auditory system of the goldfish - a member of the Otophysii - does not typify that of the majority of bony fish. Otophysans are taxonomically defined by the presence of a specific physical connection that couples the swim bladder with the inner ear. This peripheral specialization enables an enhanced sensitivity to sound pressure and to high frequencies relative to fish species that lack otophysic coupling [Popper and Fay, 2011]. The enhanced auditory sensitivity enabled by peripheral specialization must be reflected by neural specializations. How, then, may our results inform future analyses of fish without otophysic coupling?

One point we can consider derives from the independently evolved types of otophysic coupling present in widely divergent fish taxa [reviewed in Popper et al., 2003, and in Braun and Grande, 2008]. Comparative analyses of these taxa reveal a neural specialization that all share: hypertrophy of the dorsal-most region of the DO [McCormick, 1999, 2011], i.e. the region of the dDO that includes the Ld population and the Md population. Thus, the dorsal-most region of the DO includes one lateral population $(\mathrm{Ld})$ that, at least in the goldfish, receives firstorder input from the mechanosensory LL as well as from the otolithic end organs, and one medial population (Md) that receives input only from the inner ear. In otophysans, the saccule is believed to be the dominant sound pressure receptor, and it is the saccule that provides exclusive input to Md somata. Like the Md, the other medial populations in the $\mathrm{dDO}$, the Mvtf and the Mvo, receive firstorder input only from the otolithic end organs but not from the mechanosensory LL. We do not know whether any of the three medial dDO populations in the goldfish function primarily or exclusively in sound pressure processing, although the $\mathrm{Md}$ is a potential candidate by virtue of its exclusive saccular input. However, we can speculate that any of the medial populations present in goldfish that are also present in other species are unlikely to get firstorder LL input.

Within a given clade, species from divergent taxa can be expected to share features that were established early in evolutionary history. Such features constitute the fundamental scaffolding upon which further evolution takes place. Acoustic particle motion detection by the inner ear otolithic end organs, acting as inertial accelerometers, is the primitive and universal method by which sound stimulates the inner ear of all fish, including the goldfish. However, sonic sources also produce local incompressible flows. Therefore, the low-frequency sensitivity of the mechanosensory LL to incompressible flows of a sound source could also be a primitive feature in osteichthyan/ gnathostome fishes. If so, then we would predict that auditory neurons supplied by both modalities are components of the primitive central scaffolding of the auditory system. Notably, neurons retrogradely labeled from the auditory midbrain that resemble the goldfish Ld-f population (which we suggest above likely integrates LL and otolithic end organ inputs) are clearly present dorsally in the descending nucleus in teleosts from a variety of taxa [Kozloski and Crawford, 1998; O'Marra and McCormick, 1999; Bass et al., 2000, 2001; Tomchik and Lu, 2005; Maruska and Tricas, 2009]. Thus, the overlapping sensitivity of the mechanosensory LL and the inner ear, and the input of both modalities to the lateral $\mathrm{dDO}$, may both be primitive features of the piscine auditory system.

Anatomical, physiological, and behavioral studies continue to refine our understanding of the auditory and mechanosensory LL systems. Studies in the early twentieth century that merged them into a single functional unit were followed by those that highlighted their distinctions. Present thinking mirrors both extremes, recognizing areas of divergence and convergence in their central anatomy and functions. Collectively, recent studies and ongoing efforts are clarifying our understanding of the biological roles of the inner ear auditory and the mechanosensory LL systems, including their functional interplay.

\section{Acknowledgements}

We thank Mark Braford and Sheryl Coombs for valuable comments on this paper.

This research was supported by the Department of Biology, the Department of Neuroscience, and a Senior Research Scholar Award from the dean's office of Oberlin College.
McCormick/Gallagher/Cantu-Hertzler/ Woodrick 


\section{References}

Ayers H (1892): Vertebrate cephalogenesis. 2. A Edds-Walton PL, Fay RR (2005): Projections to contribution to the morphology of the vertebrate ear, with a reconsideration of its functions. J Morphol 6:1-360.

Bass AH, Bodnar DA, Marchaterre MA (2000): Midbrain acoustic circuitry in a vocalizing fish. J Comp Neurol 419:505-531.

- Bass AH, Bodnar DA, Marchaterre MA (2001): Acoustic nuclei in the medulla and midbrain of the vocalizing Gulf toadfish (Opsanus beta). Brain Behav Evol 57:63-79.

Beard J (1884): On the segmental sense organs of the lateral line, and on the morphology of the vertebrate auditory organ. Zool Anz 7:123226.

Bell CC (2002): Evolution of cerebellum-like structures. Brain Behav Evol 59:312-326.

Bell CC, Bodznick D, Montgomery J, Bastian J (1997): The generation and subtraction of sensory expectations within cerebellum-like structures. Brain Behav Evol 50(suppl 1):1731.

Bell CC, Han V, Sawtell NB (2008): Cerebellumlike structures and their implications for cerebellar function. Annu Rev Neurosci 31:1-24.

Bodznick D, Montgomery JC, Carey M (1999) Adaptive mechanisms in the elasmobranch hindbrain. J Exp Biol 202:1357-1364.

Braun CB, Coombs S (2010): Vibratory sources as compound stimuli for the octavolateralis systems: dissection of specific stimulation channels using multiple behavioral approaches. J Exp Psychol 36:243-257.

Braun CB, Coombs S, Fay RR (2000): What is the nature of multisensory interaction between octavolateralis sub-systems? Brain Behav Evol 59:162-176.

Braun CB, Grande T (2008): Evolution of peripheral mechanisms for the enhancement of sound reception; in Webb JF, Fay RR, Popper AN (eds): Fish Bioacoustics. New York, Springer, pp 99-144.

Braun CB, Sand O (2014): Functional overlap and nonoverlap between lateral line and auditory systems; in Coombs S, Bleckmann H, Fay RR, Popper AN (eds): The Lateral Line. New York, Springer, pp 281-312.

Coffin AB, Zeddies DG, Fay RR, Brown AD, Alderks PW, Bhandiwad AA, Mohr RR, Gray, MD, Rogers PH, Sisneros JA (2014): Use of the swim bladder and lateral line in near-field sound source localization by fish. J Exp Biol 217:2078-2088.

Coombs S, Montgomery JC (1999): The enigmatic lateral line system; in Fay RR, Popper AN (eds): Comparative Hearing: Fish and Amphibians. New York, Springer, pp 319-362.

Dijkgraaf S (1963): The functioning and significance of the lateral line organs. Biol Rev 38: 51-105.

Eaton RC, Lee RK, Foreman MB (2001): The Mauthner cell and other identified neurons of the brainstem escape network of fish. Prog Neurobiol 63:467-485. bimodal sites in the torus semicircularis of the toadfish, Opsanus tau. Brain Behav Evol 66: 73-87.

Edds-Walton PL, Matos SR, Fay RR (2013): Does the magnocellular octaval nucleus process auditory information in the toadfish, Opsanus tau? J Comp Physiol A Neuroethol Sens Neural Behav Physiol 199:353-363.

Fay RR, Edds-Walton PL (2001): Bimodal units in the torus semicircularis of the toadfish (Opsanus tau). Biol Bull 201:280-281.

Fay RR, Edds-Walton PL (2008): Structures and functions of the auditory nervous system of fishes; in Webb JF, Fay RR, Popper AN (eds): Fish Bioacoustics. New York, Springer, pp 49-97.

Finger TE (1986): Electroreception in catfish: behavior, anatomy, and electrophysiology; in Bullock TH, Heiligenberg W (eds): Electroreception. New York, Wiley, pp 287-317.

- Harris GG, van Bergeijk WA (1962): Evidence that the lateral line organ responds to nearfield displacements of sound sources in water. J Acoust Soc Am 34:1831-1841.

Higgs DM, Radford CA (2013): The contribution of the lateral line to 'hearing' in fish. J Exp Biol 216:1484-1490.

Higgs DM, Radford CA (2016): The potential overlapping roles of the ear and lateral line in driving 'acoustic' responses. Adv Exp Med Biol 877:255-270.

Kozloski J, Crawford JD (1998): Functional neuroanatomy of auditory pathways in the sound-producing fish Pollimyrus. J Comp Neurol 401:227-252.

Larsell O (1967): The Comparative Anatomy and Histology of the Cerebellum from Myxinoids Through Birds. Minneapolis, University of Minnesota Press.

Maruska KP, Tricas TC (2009): Central projections of octavolateralis nerves in the brain of a soniferous damselfish (Abudefduf abdominalis). J Comp Neurol 512:628-650.

Mayser P (1882): Vergleichend anatomische Studien über das Gehirn der Knochenfische mit besonderer Berücksichtigung der Cyprinoiden. Z Wiss Zool 36:259-364.

McCormick CA (1999): Anatomy of the central auditory pathways of fish and amphibians; in Fay RR, Popper AN (eds): Comparative Hearing: Fish and Amphibians. New York, Springer, pp 155-217.

McCormick CA (2011): Auditory/lateral line CNS: anatomy; in Farrell AP (ed): Encyclopedia of Fish Physiology: from Genome to Environment. San Diego, Academic Press, vol 1, pp 283-291.

McCormick CA, Braford MR Jr (1993): The primary octaval nuclei and inner ear afferent projections in the otophysan Ictalurus punctatus. Brain Behav Evol 42:48-68.
McCormick CA, Braford MR Jr (1994): Organization of inner ear endorgan projections in the goldfish, Carassius auratus. Brain Behav Evol 43:189-205.

McCormick CA, Wallace A (2012): Otolith end organ projections to auditory neurons in the descending octaval nucleus of the goldfish, Carassius auratus: a confocal analysis. Brain Behav Evol 80:41-63.

Mirjany M, Preuss T, Faber DS (2011): Role of the lateral line mechanosensory system in directionality of goldfish auditory evoked escape response. J Exp Biol 214:3358-3367.

Montgomery JC, Bodznick D (1993): Hindbrain circuitry mediating common mode suppression of ventilatory reafference in the electrosensory system of the little skate Raja erinacea. J Exp Biol 183:203-215.

Montgomery JC, Bodznick D (1994): An adaptive filter cancels self-induced noise in the electrosensory and lateral line mechanosensory systems of fish. Neurosci Lett 174:145-148.

Montgomery JC, Bodznick D (1999): Signals and noise in the elasmobranch electrosensory system. J Exp Biol 202:1349-1355.

New JG, Coombs S, McCormick CA, P. E. Oshel PE (1996): Cytoarchitecture of the medial octavolateralis nucleus in the goldfish, Carassius auratus. J Comp Neurol 366:534-546.

$>$ Oertel D, Young ED (2004): What's a cerebellar circuit doing in the auditory system? Trends Neurosci 27:104-110.

O’Marra SK, McCormick CA (1999): Organization and connections of the dorsal descending nucleus and other presumed acoustic areas in the brainstem of the teleost fish, Astronotus ocellatus. Hear Res 129:7-19.

Popper AN, Fay RR (2011): Rethinking sound detection by fishes. Hear Res 273:25-36.

$\checkmark$ Popper AN, Fay RR, Platt C, Sand O (2003): Sound detection mechanisms and capabilities of teleost fishes; in Collin SP, Marshall NJ (eds): Sensory Processing in Aquatic Environments. New York, Springer, pp 3-38.

Puzdrowski RL (1989): Peripheral distribution and central projections of the lateral line nerves in goldfish, Carassius auratus. Brain Behav Evol 34:110-131.

Radford CA, Mensinger AF (2014): Anterior lateral line nerve encoding to tones and playback vocalisations in free-swimming oyster toadfish, Opsanus tau. J Exp Biol 217:15701579.

Sand O (1981): The lateral line and sound reception; in Tavolga WN, Popper AN, Fay RR (eds): Hearing and Sound Communication in Fishes. New York, Springer, pp 459-478.

Schellart NAM, Kroese ABA (1989): Interrelationship of acousticolateral and visual systems in the teleost midbrain; in Coombs S, Görner P, Münz H (eds): The Mechanosensory Lateral Line: Neurobiology and Evolution. New York, Springer, pp 421-444. 
-Straka H, Baker R (2013): Vestibular blueprint in early vertebrates. Front Neural Circuits 7:182.

- Szabo TM, McCormick CA, Faber DS (2007): Otolith endorgan input to the Mauthner neuron in the goldfish. J Comp Neurol 505:511525.

Tomchik SM, Lu Z (2005): Octavolateral projections and organization in the medulla of a teleost fish, the sleeper goby (Dormitator latifrons). J Comp Neurol 481:96-117.

van Bergeijk WA (1967): The evolution of vertebrate hearing; in Neff WD (ed): Contributions to Sensory Physiology. New York, Academic Press, pp 1-49.
Webb JF, Montgomery JC, Mogdans JC (2008): Bioacoustics and the lateral line system of fishes; in Webb JF, Fay RR, Popper AN (eds): Fish Bioacoustics. New York, Springer, pp 145-182.

Weeg MS, Bass AH (2000): Central lateral line pathways in a vocalizing fish. J Comp Neurol 418:41-64.

Weeg MS, Bass AH (2002): Frequency response properties of lateral line superficial neuromasts in a vocal fish, with evidence for acoustic sensitivity. J Neurophysiol 88:1252-1262.

Wullimann MF, Grothe B (2014): The central nervous organization of the lateral line system; in Coombs S, Bleckmann H, Fay RR, Popper AN (eds): The Lateral Line. New York, Springer, pp 195-251.
Yamamoto N, Kato T, Okada Y, Somiya H (2010): Somatosensory nucleus in the torus semicircularis of cyprinid teleosts. J Comp Neurol 518:2475-2502.

-Young ED, Spirou GA, Rice JJ, Voight HF, Rees A (1992): Processing of complex sounds by the auditory system. Philos Trans R Soc Lond B Biol Sci 336:407-413.

Zeddies DG, Fay RR, Alderks PW, Shaub KS, Sisneros JA (2010): Sound source localization by the plainfin midshipman fish, Porichthys notatus. J Acoust Soc Am 127:3104-3113.

Zupanc G (1998): An in vitro technique for tracing neuronal connections in the teleost brain. Brain Res Brain Res Protoc 3:37-51. 